\title{
Vascularized Dartos Flap in Conjunction with Tubularized Incised Plate Urethroplasty: Single versus Double Flaps for Management of Distal Hypospadias
}

\author{
Ayman Safwat ${ }^{\mathrm{a}} \quad$ Ahmed M. Al-Adl ${ }^{\mathrm{a}, \mathrm{b}} \quad$ Tarek El-Karamany $^{\mathrm{a}}$

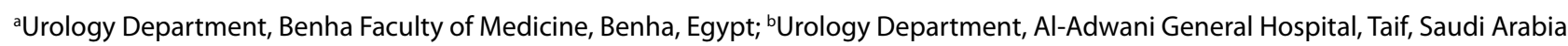

\section{Key Words}

Hypospadias • Tubularized incised-plate $\cdot$ Dartos flap •

Fistula • Urethroplasty

\begin{abstract}
Objective: To compare the results of Snodgrass repair with single versus double vascularized dartos pedicle flap for neouretheral coverage. Patients and Methods: Fifty-eight pediatric patients with mean age $41.5 \pm 21$ months (range 9-96 months) underwent primary hypospadias repair, 39 uncircumcised and 19 circumcised, classified into 2 groups according to coverage of the neourethra. Single layer coverage (Group I) was performed in 28 (48.3\%) while double layers coverage (Group II) was done in 30 (51.7\%) cases. Results: After mean follow-up 8.6 \pm 5.4 months (range 3-24 months), good cosmetic results with vertical slit like meatus at the tip of conical shaped glans were obtained in 53 cases (91.4\%). Totally 5 cases occurred postoperative complications, of which 4 cases in Group I [2 (7.1\%) with urethrocutaneous fistula, 1 (3.6\%) with meatal stenosis and 1 (3.6\%) with skin necrosis], 1 case in Group II [glanular dehiscence (3.3\%)]. No fistula was observed in Group II. Conclusion: The Snodgrass tubularized incised-plate repair in conjunction with double layer coverage of the neourethra could be considered the procedure of choice for distal hypospadias with low complications rate especially urethrocutaneous fistula.
\end{abstract}

Copyright $\odot 2012$ S. Karger AG, Basel

\section{KARGER}

Fax +4161306 1234

E-Mail karger@karger.ch

www.karger.com
(C) 2012 S. Karger AG, Basel

$1015-9770 / 12 / 0062-0067 \$ 26.00 / 0$

Accessible online at:

www.karger.com/cur

\section{Introduction}

During the last century, almost 200 surgical procedures for hypospadias repair have been described [1]. Despite obvious surgical advances in hypospadias repair no single technique has been without complication. Since its introduction in 1994, the Snodgrass or tubularized incised urethral plate hypospadias repair [2] has been applied to virtually every type of hypospadias defect distal and midshaft and considered the procedure of choice [3] as it is versatile, easy to do and has a good cosmetic outcome with a vertically orientated meatus as in a normal circumcised penis. Several series have reported excellent functional and cosmetic results with Snodgrass repair [4]. The most common and particularly annoying complication is urethrocutaneous fistula rates have still been reported to be as high as 5\% from large center, multiple surgeon studies [5] and 16\% from smaller center study [6]. This has made many authors to suggest that urethral covering should be part of Snodgrass procedure to avoid urethrocutaneous fistula as a single layer $[7,8]$ or as a double layers $[9,10]$ that could be retrieved from dorsal or ventral aspects of the penile shaft.

The purpose of the present report was to present our experience with tubularized incised-plate (TIP) urethroplasty for distal hypospadias with comparing single and double barrier dartos flaps coverage of the neourethra. 


\section{Patients and Methods}

Between May 2005 and October 2010, 58 pediatric patients underwent primary hypospadias surgery, with mean age $41.5 \pm$ 21 months (range 9-96 months). Out of those, 39 were uncircumcised while 19 cases were previously circumcised. All cases managed by Snodgrass technique in conjunction with coverage of the neourethra by single layer (Group I) or double layers coverage (Group II) to be harvested from dorsal prepuce or from ventral vascularized dartos pedicle flap. Informed consent was obtained from all patients' sponsors and the procedure and possible risks were explained thoroughly according to declaration of Helsinki.

\section{Surgical Technique}

A circumferential incision is made $5 \mathrm{~mm}$ below the coronal margin and in the midline to go round the native urethral meatus with extreme care taken to incise only through the dermis on top of the distal urethra. Degloving of the shaft skin keeping all subdermal vascularized tissue attached to the mucosal collars, urethra and lateral urethral corporeal grooves intact. Parallel incisions along the visible margins of the urethral plate separate its distal aspect from the glans wings and with the surgeon and assistant holding counter-traction, midline relaxing incision was done using tenotomy scissors to incise through the epithelium and connective tissue to near the corpora from within the meatus to the distal extent of the plate. Depth of the relaxing incision is determined by the extent that the plate is grooved. A flat plate has a greater thickness of connective tissue under its epithelial surface and requires a deeper cut than a plate that is naturally deeply clefted with a minimal amount of connective tissue over the corpora [11]. After an adequate incision is made, the width of the plate increased to allow creation of the neourethra without need for skin flaps. A 6 Fr silastic stent is passed into the bladder and secured to the glans traction suture. The urethral plate is then tubularized beginning at point near the midsection of the glans so that the neomeatus will have an oval configuration with an adequate diameter. Closure of the first layer is done in a running subcuticular fashion using $6 / 0$ polygalactin sutures with efforts made to invert the epithelium completely. The second layer incorporates the carefully preserved periurethral vascularized tissue. A formal vascularized dartos flap is then harvested from the subcutaneous tissue of the preputial skin in uncircumcised cases. After making a transverse skin incision in the dorsal skin, sharp dissection start from the level of the corona and directed distally taking all the vascularized dartos tissue after de-epithelialization. Then continue proximally having enough tissue to be transferred to the ventral surface, divided vertically to be rolled laterally from both side of the penile shaft and overlapped on the ventral surface over the neourethra in double layer fashion to cover the entire neourethra (fig. 1).

In previously circumcised patients, lateral based vascularized pedicle is marked with traction sutures on the proximal shaft at a point that allows reflection of the pedicle up into the glans to the distal aspect of the urethroplasty after proximal dissection. The pedicle can be harvested from either side of the urethral corporeal groove. Extreme care must be taken with distal dissection of the pedicle to preserve vascular supply. The visible vascular supply to the pedicle is usually from the vascular pedicle of the mucosal collar. After it is freed from the proximal shaft the vascularized pedicle flap is fanned out to reduce bulk and then tracked into the lateral recesses of the raised glans wings with $6 / 0$ polygalactin
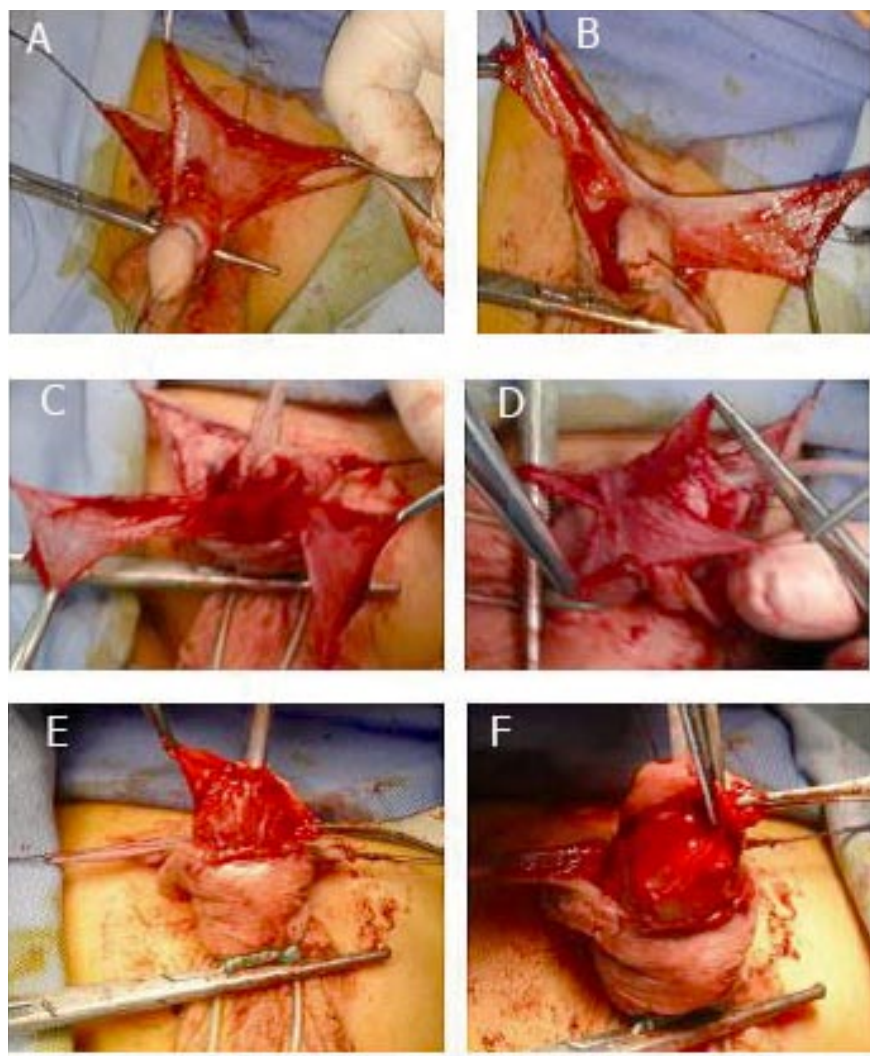

Fig. 1. A Dorsal vertical flap. B Divided vertically. C Reflected to the ventral aspect. D Overlapped on the neourethra. E Tracked to the glanular wings. F Glanular closure over the double layers.

suture. This reflected tissue provides a vascularized tissue barrier between the urethroplasty suture line and dermis and isolates urethral repair to the distal glanular area. The glans and mucosal collar are closed over the neourethra and vascularized dartos flap. If tension exists in closure of the glans, the glans incisions are deepened further to allow room for the neourethra and a tension free closure. To minimize risk of the suture tracts all skin surfaces are sutured by subepithelial technique [12]. A dressing is applied and the stent allowed dripping into diapers for 5 to 7 days.

\section{Statistical Analysis}

Statistical analysis was performed using SPSS software version 16 for windows. Numerical data are summarized as mean \pm SD. Categorical data are summarized as percents. All $\mathrm{p}$ values were 2 sided and considered significant at $\mathrm{p} \leq 0.05$.

\section{Results}

The series included 58 boys aged $41.5 \pm 21$ months (range 9-96 months) who underwent primary hypospa- 
Table 1. Number (\%) of 58 cases regarding intraoperative position of hypospadiac meatus, layers of coverage of the neourethra and presence of postoperative complications

\begin{tabular}{lccc}
\hline & Group I & Group II & Total \\
\hline Uncircumcised & & & \\
$\quad$ Coronal & $5(18)$ & $6(20)$ & $11(19)$ \\
$\quad$ Subcoronal & $4(14)$ & $9(30)$ & $13(22)$ \\
$\quad$ Distal penile & 0 & $15(50)$ & $15(26)$ \\
Circumcised & & & \\
$\quad$ Coronal & $14(50)$ & & $14(24)$ \\
$\quad$ Subcoronal & $5(18)$ & & $5(9)$ \\
Complications & & & \\
$\quad$ Yes & $4(14.3)$ & $1(3.3)$ & $5(8.6)$ \\
$\quad$ None & $24(85.7)$ & $29(96.7)$ & $53(91.4)$ \\
Type of complication & & & \\
$\quad$ Urethrocutaneous fistula & $2(7.1)$ & 0 & $2(3.4)$ \\
$\quad$ Meatal stenosis & $1(3.6)$ & 0 & $1(1.7)$ \\
$\quad$ Glanular dehescence & 0 & $1(3.3)$ & $1(1.7)$ \\
$\quad$ Skin necrosis & $1(3.6)$ & 0 & $1(1.7)$ \\
Total & $28(48.3)$ & $30(51.7)$ & $58(100)$ \\
& & &
\end{tabular}

dias repair and mean follow-up period $8.9 \pm 5.9$ months (ranged 3-24 months). The hypospadiac meatus was coronal in 25 patients (43\%), subcoronal in 18 patients $(31 \%)$ and distal penile in 15 patients $(26 \%)$. There were 39 (67\%) uncircumcised and 19 (33\%) circumcised patients. Five patients had chordee that was in 4 cases limited to either skin, dartos fascia or periurethral tissue and after degloving the chordee was corrected while in 1 patients with mid penile hypospadias they required dorsal placation of the tunica albuginea.

All hypospadias repairs were completed in one stage with no intraoperative urethral injuries or complications had been observed. Table 1 shows the intraoperative position of the hypospadiac meatus in 39 uncircumcised and 19 circumcised cases and classification according to the layers of coverage of the neourethra.

According to the coverage layers single or double coverage, Group I included 28 patients, 9 uncircumcised (5 coronal and 4 subcoronal) and 19 circumcised (14 coronal, 5 subcoronal) were repaired by TIP combined with one layer coverage of the neourethra. In the 9 uncircumcised cases, the single layer was harvested from dorsal prepuce. In 19 circumcised cases the lateral urethral corporeal groove was the site to harvest the single coverage.

Dartos Flap with TIP Urethroplasty
Group II included 30 uncircumcised cases ( 6 coronal, 9 subcoronal and 15 with distal penile hypospadias). The 2 layers were harvested from the dorsal prepuce, divided vertically and rolled from both sides of the shaft and overlapped on the ventral aspect of the neourethra.

After mean follow-up 8.6 \pm 5.8 months (range 3-24 months), good cosmetic results with vertical slit like meatus at the tip of conical-shaped glans were obtained in a total of 53 cases $(91.4 \%)$ while complications were found in 5 cases, 4 cases (14.3\%) in Group I and 1 case in Group II that developed glanular dehiscence with insignificant difference between the 2 groups $(\mathrm{p}=0.18$, Fisher's Exact Test) although there was significant risk estimate for Group I patients (Odds ratio 0.566 and 95\% CI 0.334 - 0.961). In Group I, there were 2 cases with urethrocutaneous fistula $(2 / 28,7.1 \%), 1$ case with meatal stenosis $(1 / 28,3.6 \%)$ and 1 case with skin necrosis $(1 / 28$, $3.6 \%)$.

Urethrocutaneous fistula developed in the first month postoperative in subcoronal hypospadias 1 circumcised and 1 uncircumcised, those cases were re-operated after 6 months by surgical excision of the fistula tract and multilayer closure of the urethra and skin defect. The case with glanular dehiscence was corrected after 6 months. Meatal stenosis responded well to meatal dilatation with no need for surgical intervention.

\section{Discussion}

Since its introduction in 1994 [3], the Snodgrass or tubularized incised urethral plate hypospadias repair has been applied to virtually every type of hypospadias defect. The urethral plate being vascularized tissue with a good muscular backing, rich in nerve supply and with gland forming capability, this probably explains the success of the procedure and with preservation of the urethral plate taking the advantage of this extensive blood supply under the urethral plate [13]. The risk of urethral stricture formation and potential for meatal stenosis are the main controversies about the procedure. Technical errors that can lead to meatal stenosis may be failure to incise the plate deeply enough and sewing the plate too far distally during the process of tubularization as stated by Snodgrass [14]. A major concern in the TIP hypospadias repair is preventing urethrocutaneous fistula. Fistula formation begins early in the healing process after ventral urethral repair where factors that predispose to fistula formation are incorporation of urethral mucosa in the ventral repair and rapid migration of urethral mucosa

Curr Urol 2012;6:67-70 
and skin epithelium into suture tracts hence the importance of a multi-layered repair and extra-mucosal suture technique are thus emphasized with respect to urethral repair [15]. The observation of Bleustein et al. [16] that inflammatory and desmoplastic reactions are more prominent around suture material along the ventral urethral closure is also important since these reactions may help explain fistula formation. Accepted fistula rates in large hypospadias series 2 to 14\% [17]. Many procedures have been described to achieve vascularized coverage of the suture line. Covering urethroplasty with vascularized tissue as part of repair is well described and considered the perfect repair for virgin distal hypospadias cases [8-11, 18]. After tubularization, a single layer covering not only provides a vascularized tissue barrier between the urethroplasty suture line and dermis, but also isolates urethral repair to the distal glanular area [19].

In present study, we evaluated the results after TIP in conjunction with neourethral coverage with single or double layer barrier. Most patients have a satisfactory cosmetic and function results, with vertical slit like meatus at the tip of conical shaped glans in 53 cases (91.4\%).
The incidence of urethrocutaneous fistula in the present series was found in 2 cases out of 28 (7.1\%) where this was associated with cases in whom single layer coverage was used. The double layer coverage of the neourethra reduced the risk of urethrocutaneous fistula where in Group II no fistula was observed, this in agree with the opinion of many authors that the use of double layers for covering the neourethra was considered as the procedure of choice [9] as it is safe and significantly reduces the incidence of postoperative fistula [10]. In Group II, one case of glanular dehiscence was observed this case could be due to infection at repair.

\section{Conclusions}

The conjunction of double layer coverage of the neourethra with the standard Snodgrass technique (TIP) reduced the risk of urethrocutaneous fistula and should be considered the management of choice for virgin cases with distal hypospadias whenever possible.

\section{References}

1 Duckett JW: MAGPI (meatoplasty and glanuloplasty): a procedure of subcoronal hypospadias. Urol Clin North Am 1981;8:513-519.

$\checkmark 2$ Snodgrass W: Tabularized, incised plate urethroplasty for distal hypospadias. J Urol 1994;151:464-465.

3 De Filippo RE, Bauer SB: New surgical techniques in pediatric urology. Curr Opin Urol 2001;11:591-596.

4 Snodgrass W, Koyle M, Manzoni G, Hurwitz R, Caldamone A, Ehrlich R: Tubularized incised plate hypospadias repair: results of multicenter experience. J Urol 1996;156: 839-841.

$\checkmark 5$ Borer JG, Bauer SB, Peters CA, Diamond DA, Atala A, Cilento BG Jr, Retik AB: Tubularized incised plate urethroplasty: expanded use in primary and repeat surgery for hypospadias. J Urol 2001;165:581-585.

6 Guralnick ML, al-Shammari A, Williot PE, Leonard MP: Outcome of hypospadias repair using the tubularized incised plate urethroplasty. Can J Urol 2000;7:986-991.

-7 Djordjevic ML, Perovic SV, Vukadinovic VM: Dorsal dartos flap for preventing fistula in the Snodgrass hypospadias repair. BJU Int 2005;95:1303-1309.
8 Hayashi Y, Kojima Y, Nakane A, Kurokawa S, Tozawa K, Kohri K: Ventral based dartos flap for the prevention of the urethrocutaneous fistula urethroplasty. Int J Urol 2007; 14:725-728.

9 Mustafa M, Wadie BS, Abol-Enein H: Standard Snodgrass technique in conjunction with double-layer covering of the neourethra with dorsal dartos flap is the therapy of first choice for hypospadias. Int Urol Nephrol 2008;40: 573-576.

10 Appignani A, Prestipino M, Bertozzi M, Nardi N and Falcone F: Double-cross flap protection: new technique for coverage of neourethra in hypospadias repair. J Urol 2009;182: 1521-1527.

$\checkmark 11$ Holland AJ, Smith GH: Effect of the depth and width of urethral plate on tabularized incised plate urethroplasty. J Urol 2000;164: 489-491.

12 Snodgrass W: Suture tracks after hypospadias repair. BJU Int 1999;84:843-844.

13 Erol A, Baskin LS, Li YW, Liu WH: Anatomical studies of the urethral plate: why preservation of the urethral plate is important in hypospadias repair. BJU Int 2000;85:728734
14 Snodgrass WT: Re: Effect of the depth and width of the urethral plate on tubularized incised plate urethroplasty. J Urol 2001;166: 633

15 Edney MT, Lopes JF, Schned A, Ellsworth PI, Cendron M: Time course and histology of urethrocutaneous fistula formation in a porcine model of urethral healing. Eur Urol 2004;45: 806-810.

16 Bleustein CB, Esposito MP, Soslow RA, Felsen D, Poppas DP: Mechanism of healing following the Snodgrass repair. J Urol 2001; 165:277-279.

17 Ulman I, Erikci V, Avanoglu A, Gokdemir A: The effect of suturing technique and material on complication rate following hypospadias repair. Eur J Pediatr Surg 1997;7:156-157.

18 Cheng EY, Vemulapalli SN, Kropp BP, Pope JC 4th, Furness PD 3rd, Kaplan WE, Smith DP: Snodgrass hypospadias repair with vascularized flap: the perfect repair for virgin cases of hypospadias? J Urol 2002;168:17231726.

19 Furness PD 3rd, Hutcheson J: Successful hypospadias repair with ventral based vascular dartos pedicle for urethral coverage. J Urol 2003;169:1825-1827. 